\title{
21. Improving Water Planning Processes: Priorities for the next five years
}

\author{
Mark Hamstead
}

\section{Introduction}

The Murray-Darling Basin Plan will be an overarching statutory document that relies on a range of subsidiary arrangements for its implementation.

Water-resource plans are to be prepared at a regional level by basin State governments ${ }^{1}$ and accredited by the Commonwealth minister. Requirements for accreditation will be set out in the Basin Plan. The timing of the preparation of these varies from 2012 to 2019, depending on when current water-allocation plans come up for review. Regional strategic environmental watering plans will also be developed by basin State governments within one year of the making of the Basin Plan.

The Commonwealth will be investing heavily through buybacks of entitlements or other means to discharge its obligations in regard to funding reductions under the Water Act 2007 risk-sharing arrangements. This should be done in a manner consistent with best achieving Basin Plan outcomes.

Lastly, collaborative arrangements will be needed to coordinate the actions of multiple parties. Government and non-governmental environmental waterholders will need to collaborate in managing water to achieve Basin Plan outcomes, and various State and Commonwealth agencies will need to collaborate in relation to complementary management of land, and facilitating structural adjustment.

Achieving the objectives of the Plan-and gaining the expected value from major reductions in water extraction - is heavily reliant on the effectiveness of these arrangements.

At the time of writing, only the Guide to the proposed Basin Plan (MDBA 2010) had been released, with the Draft Plan to follow after further consultation. The

1 References to 'basin States' in this chapter means each of the Murray-Darling Basin States and the Australian Capital Territory. 
Guide sets out in plain text what the Murray-Darling Basin Authority (MDBA) proposes to put into the Draft Plan. It is assumed that the Plan will generally conform to this, though details might change.

Under the Basin Plan, water-resource plan areas encompass whole river valleys. State-based water-resource plans that will be accredited under the Basin Plan are expected to be an amalgamation of one or more instruments prepared under existing State legislation. For example, an accredited water-resource plan could be a package of one or more State water plans covering different water resources within the area, some statutory orders, a natural-resource management plan and a regional water-quality strategy.

This chapter focuses on aspects of implementing the Basin Plan that could make a big difference to its effectiveness. Implementing the diversion limits will clearly be a central aspect of water-resource plan accreditation and compliance, and will depend on the existing Basin Cap compliance arrangements. Likewise, there is a strong and worthwhile emphasis on adaptive learning and building resilience in environmental management. Rather than dwell on these already heavily emphasised matters, in this chapter, other matters that are-in the author's view - less well addressed but still essential for achieving the desired outcomes of the Basin Plan are discussed. These are

- greater integration of groundwater and surface-water management

- greater integration of natural-resource investment plans and water-allocation plans

- supporting increased resilience in the irrigation industry

- improving the rigour of water-resource planning

- governance at a regional level.

\section{Greater Integration of Groundwater and Surface-Water Management}

Until recently, water plans for groundwater systems have been prepared separately to those for surface-water systems, and have largely ignored the effects each can have on adjoining connected systems. The Basin Plan notes that across the Basin more than 60 per cent of groundwater systems were assessed as being highly connected to surface-water systems.

Not recognising the cross-connection effects of water extraction has meant that there are unconsidered and unaddressed impacts. Studies over recent years have shown that time-lagged effects of past groundwater extraction on current and 
future surface-water availability are substantial in many areas. The benefits obtained by the past groundwater users are thus offset in part by the lost future benefits to surface-water users and ecosystems.

The Basin Plan has addressed this by limiting increased extraction of groundwater in systems that are connected to rivers. Integrated management across connected groundwater and surface-water systems can, however, go beyond this to deliver more optimised outcomes.

If there is to be integrated management of connected water systems then either they must be addressed in a single water plan or, if they are in separate plans, they must include appropriate linkages. It is possible to achieve a level of integration of management through linking plans, but it is more difficult than where the water systems are in a combined plan. Where the plans are totally separate, the making and review of the plans are generally unsynchronised, making development of coordinated-management strategies challenging.

The spatial scale of planning is important for integration. In the Basin States, water planning is moving towards a larger scale and inclusion of both surface and groundwater. In Queensland, water plans are being developed mostly at a catchment or multi-catchment scale. While the early plans addressed only major rivers within the catchments, they have now in several areas been amended to include major aquifers, and some recent plans include both ground and surface water. In New South Wales, the most recent 'macro' plan — the Peel-includes all the surface and groundwater in the Peel Valley. Victoria is currently developing its first plan that addresses both surface and groundwater.

There seems to be little reason why connected aquifers should not be included in the same water plan as the rivers, even if in some parts time lags are large. Ideally, all jurisdictional water plans within a basin water-resource plan area should be pulled into a single instrument. Decisions can then be made within the plan development process on the level of integration of management that is optimal. At a minimum, narrow, highly transmissive unconfined alluvial aquifers should be brought into the same plan as the rivers to which they are connected.

With planning for connected systems combined in this way, it opens up the ability to develop and apply coordinated strategies and rules. These will vary depending on the nature of the connection - whether a unit of groundwater extraction results in a unit less water in the river or a lesser amount, and how long the time lag is between groundwater extraction and impact on river flows. Strategies and rules that can be used to optimise cross-system water management include linked caps on water rights or extraction, linked seasonal allocation determinations, linked restrictions on rates of extraction tied to water levels or 
flow triggers, providing for trade of water entitlement and/or allocation across the connection, constraining the location of groundwater extraction to alter the timing or extent of cross-connection impacts, and provision for measures such as works, purchase of water entitlements and structural adjustment to offset cross-connection impacts.

The Basin Plan does not limit more integrated management occurring, and indeed provides flexibility to adjust for more optimal integrated solutions. For example, the Guide notes that 'some groundwater systems are highly connected to surface-water systems, but may be capable of sustaining further take. In these SDL [sustainable diversion limit] areas, further take could be feasible provided that there is a corresponding reduction in surface water take to offset the resultant impact on streamflow' (MDBA 2010:139). Also, basin water-resource plan areas provide an opportunity for jurisdictional water-allocation plans for groundwater and surface water to be combined.

It would be worthwhile for the Basin Plan to go a step further and require an assessment of possible integration strategies as part of water-resource plan accreditation.

\section{Greater Integration of Natural-Resource Investment Plans and Water-Allocation Plans}

All basin States have processes for water-allocation planning and naturalresource management investment planning. While these two separate planning processes serve different purposes, there is an area of overlap. Both include provisions relating to the maintenance or improvement in the condition of freshwater aquatic ecosystems (rivers, aquifers, wetlands, and so on).

Achievement of aquatic ecosystem outcomes is dependent on many factors. For example, the condition of a river can be affected by a combination of altered flow regime, channel modification, poor water quality, introduced exotic flora and fauna, loss of riparian vegetation, stock access, in-stream obstructions to fish passage, and catchment disturbance. Often addressing only one of them will not achieve the intended result, and might be ineffective because of inaction to address the others.

For the Basin Plan, provision of additional flows to preserve water-dependent ecosystems might be ineffective if, for example, those ecosystems are degraded by stock access or poor water quality. Thus, there is a need to consider all the threats together and develop coordinated plans of action. 
The Commonwealth Caring for our Country investment program includes investments in riparian vegetation, wetland conservation, catchment condition and river-form protection - through works, partnerships and education. This is prioritised through regional natural-resource management plans. As noted in Hamstead et al. (2008), coordination of this activity with water-allocation planning has varied substantially in effectiveness.

Within any planning area, there are those ecosystems that are more highly valued than others, those that are more under threat than others, and those that have greater potential for protection or recovery from damage. Effective integration requires action to be planned and coordinated in a way that takes these factors into account so as to focus investment and maximise naturalresource outcomes. Recognising that both types of planning processes require considerable resourcing and that government and community resources are limited, improved integration can also increase the return on this investment by minimising duplication and increasing synergy.

Improved integration can be achieved through a range of approaches ranging from establishing linkages between parallel processes to improve alignment, synchronising and linking the making and review of plans in parallel to combining processes into one. Victoria already does this to a large extent through the way it uses regional sustainable water strategies to coordinate regional natural river health strategies with water-allocation management. A pilot of how water-sharing plans and catchment-action plans could be better aligned was recently undertaken in New South Wales with good results (Hamstead forthcoming).

The Guide (MDBA:194) states explicitly that creating this sort of coordination is outside its scope, being ruled out by legislation. This means that it is reliant on collaboration and cooperation rather than statutory mandate. Without changing legislation, the obvious way forward is for the MDBA to work with the Commonwealth agency responsible for the Caring for our Country funding to require coordination of natural-resource investment and water plans as a prerequisite for provision of funding to States. Guidelines for doing so could be prepared.

\section{Supporting Increased Resilience in the Irrigation Industry}

Water planning is occurring in an ever-changing environment with considerable uncertainty about what the future holds. Future climate scenarios prepared by the CSIRO and others are just that-scenarios. Each scenario is intended to 
show a plausible future. They do not represent a probabilistic range or a normal distribution, with the median being most likely. There is substantial uncertainty in these forecasts, arising from assumptions made about emission scenarios and the modelling process. Not only are trends uncertain, the frequency and extent of extreme events are expected to increase.

Bates et al. (2010:11) comments that despite continuing research, 'this uncertainty cannot or will be only partially reduced'. As stated by Aerts and Droogers (in Ludwig et al. 2009:87): 'the new element in adapting to climate change in water management is an unknown future.'

With this in mind, it is clear that responding to climate change is more about dealing with uncertainty than anything else. Future scenarios provide a plausible, rationally derived range to inform thinking, but there remains the need to consider that something different again could be the reality. This requires a fundamental change in thinking and approach. Folke et al. (2002) describe this as follows:

Paradoxically, management that uses rigid control mechanisms to seek stability can erode resilience and enhance breakdown of socioecological systems...In contrast to an efficiency-driven, command-andcontrol approach, management that accepts uncertainty and seeks to build resilience can sustain social-ecological systems, especially during periods of transformation following disturbance.

The Basin Plan is commendable in placing a focus on ecosystem resilience. The first of its four major outcomes is water-dependent ecosystems in the Basin would be more able to withstand short and long-term changes in watering regimes resulting from a more variable and changing climate (MDBA:7).

It would have been, in the author's view, appropriate to have a similar outcome for water users - something like this: basin entitlement holders and communities will be more able to withstand short and long-term changes in watering regimes resulting from a more variable and changing climate.

Risk assessment and management, as described later, can contribute to achieving this end. The level of uncertainty, however, is such that future threats and events cannot all be identified or catered for. Building resilience and adaptability is the alternative approach to helping ensure the future of our communities.

Beare (in Bates et al. 2010) observes that an important strategy for handling uncertainty is to have a range of options available. In relation to water management, institutional arrangements that increase options for water users include facilitating water trade (permanent and temporary), allowing access to system storage capacity (dams or aquifers) to carry over unused annual 
allocations, supporting the construction of private storages to carry over unused allocations, facilitating use of aquifers for active storage and recovery of water, unbundling water entitlements, and facilitating conjunctive access to multiple water resources.

A culture of hedging for future uncertainty is needed-meaning that, like insurance, a reduction in short-term benefits is necessary to provide for longerterm security. This might mean, for example, water users retain more in carryover storage than they have in the past, wearing the risk that if conditions are wet it will spill.

Most farming businesses are familiar with hedging - for example, diversification of crops, consolidation of properties, maintaining financial reserves, insurance, and so on. So this is not generally new territory. What is different is a change in assumptions about water availability. Past signals from government about certainty of supply are no longer appropriate. Businesses will not put in place their own measures to deal with water-supply uncertainty if they have an expectation that the Government has thought things through and that supply will be reliable.

Where additional water-management options are provided, investment is also necessary to increase understanding and capacity to use the options effectively. The importance of capacity building should not be underestimated. Hamstead (2008:13) noted that the

general shortfall in technical support capacity and a lack of irrigator awareness of the operational aspects of modernised irrigation equipment was a major risk to any on-farm efficiency programme...there is no shortage of cases where high technology irrigation systems have been installed but failed to deliver either the promised water savings or productivity improvements... On site evaluations of irrigation systems noted a high rate of faults in either design, commissioning or operation.

The same will undoubtedly be true of any other facility provided. Capacity building is a critical and often under-resourced strategy that can be built into water planning.

The Basin Plan does provide for some important measures that can help water users build resilience. Enhanced water trading is a major element of the Plan. Greater certainty about rules and planning is another. Other important measures listed above, however - such as improved access to carry over, unbundling of water entitlements, and building capacity to use water-management tools - are not mentioned. They could be addressed through water-resource plan accreditation requirements, and through collaboration with State and Commonwealth agencies. 


\section{Improving the Rigour of Water-Resource Planning}

\section{Well-Structured Plans}

Appropriately, the Basin Plan will establish an adaptive-learning framework for managing water to achieve environmental outcomes. The benefits of this could be lost, however, if water-resource plans have poorly expressed objectives, poor internal logic and low levels of investment in monitoring, reporting and research - all of which are required so that the managers can exercise this flexibility meaningfully.

Many current basin State water plans have general aspirational objectives, which allow for wide interpretation. With such objectives, it is difficult to know whether success is being achieved or not. This ambiguity creates an expectation of a level of ecological health and water-entitlement security that is not consistent with the trade-offs inherent in the body of the plan. Monitoring programs and performance indicators are also frequently general and do not provide a clear indication of whether objectives are being achieved or not. The logic of the plan - the rationale explaining the anticipated cause-and-effect relationships between strategies and objectives - is rarely well documented.

There is a need for the discipline of specific, realistic, measurable objectives and targets, with documentation of the rationale for selecting the strategies and rules for achieving them, and monitoring and reporting aligned to measuring achievement. This applies not just to environmental watering, but to all aspects of the water-resource plan. The Basin Plan could facilitate this through the water-resource plan accreditation requirements.

\section{A Greater Emphasis on Risk Management}

Past management has tended to focus planning on typical or average conditions. What is needed is a greater focus on extreme conditions and handling what can go wrong. Risk management is a well-developed approach that is underused in water planning.

Unfortunately, the term 'risk' in the Basin planning context has become synonymous with a few specific matters that could affect future water availability in the longer term - for example, interception by farm dams, stock and domestic bores and pumps, and plantation forestry. This narrow interpretation of risk is not what is intended here. 
Risk management requires identification of threatening processes and events that could have negative consequences in relation to the achievement of plan outcomes, and assessment of their likelihood and consequence. Once these risks have been identified and evaluated, risk-mitigation measures can be identified. Risk-mitigation measures can include measures implemented well before the occurrence of events, adaptive response at the onset and during the occurrence of events, and recovery after the occurrence of events.

For example, if there is a risk of water-supply failure to a town, responses could be to do something beforehand to remove the risk (for example, add a reserve water supply), to monitor the situation and have in place a plan to implement should the event occur (for example, truck in water, or buy irrigation allocations on the market if they are available), or to decide to let the town run out (people temporarily move out and come back when the drought breaks - admittedly, an unlikely option).

Similarly, for an endangered fish that would die out in a severe drought, options could be to improve and extend habitat now so the species is less vulnerable, have an emergency plan to buy water and shore up drought refuges should the event occur, or stock up an aquarium or aquaculture pond with the fish so they can be used to restock the river after the drought.

The nature of the response would depend on the cost and feasibility of each option and the level of risk. If the risk is large, multiple mitigation options might be applied.

The Basin Plan mandates some risk-mitigation measures. It includes an emphasis on building ecosystem resilience to reduce vulnerability to future events in environmental water management, and provision for setting aside of water for essential human needs in severe droughts in the River Murray system.

Further, it requires that water-resource plans 'are robust enough to continue to operate during extreme and unprecedented events' for them to be accredited (MDBA 2010:174). To achieve this, risk management will need to be a feature of water-resource plan development. It might then be expected that there will be a rigorous risk-assessment process for each water-resource plan, and public documentation of how each identified risk will be addressed.

\section{Addressing Equity}

Equitable sharing of the costs of ecosystem maintenance and the benefits of ecosystem services is a fundamental, yet often overlooked, aspect of environmentally sustainable management. Major international conventions (Ramsar, Agenda 21, Convention on Biodiversity) all recognise that addressing 
the current needs of people in an equitable manner is essential. They also recognise that future generations must be considered. Australia's National Strategy for Ecologically Sustainable Development has as one of its three objectives to 'provide for equity within and between generations'. Protecting ecosystems is done not because they have intrinsic value, but because they provide important services to society as a whole and to future generations. Equity is the core of sustainability.

Equity and fairness are objectives common to natural-resource legislation across Australia. In its essence, water planning is fundamentally about equity informed by science, not the other way around.

Yet the methods for achieving equity are poorly defined and are not explicitly thought about. It is left largely to the skills of the planners and decision makers, and assumed that standard processes will somehow deliver it. Community and stakeholder involvement in water planning — while important to this - is not of itself sufficient. Weak equity processes drive stakeholders to bypass plan makers and resort to political processes and courts.

The Basin Plan is addressing water-sharing equity at a broad level through the establishment of diversion limits. The interests of the broader, even global, community and future generations in relation to ecosystem services are represented by statutory requirements for preserving 'key' environmental assets and functions. What will be traded off in deciding the diversion limits is the level of risk these assets and functions are exposed to, in return for economic benefits from consumptive use of water. The Basin Plan will address equity at this broad level for each water-resource plan area.

Applying the principles of procedural fairness is an essential part of achieving equity. Plan development processes should ensure that all affected parties have the opportunity to hear and understand the potential implications of the Plan for them, and have their views presented and considered in decision making. Decision making should both be and be seen to be unbiased and informed, and open to cross-examination. Transparency and openness at all stages of the process are essential.

It remains to be seen how well these principles will be applied in finalising the Basin Plan. Certainly, one challenging area is explaining in ways that can be understood by the broader community what is at stake in terms of ecosystem services if no action is taken, and how this might effect the wellbeing of them and future generations.

Whatever the result is, there will still be another level of equity decisions to be made in water-resource plans, in relation to the sharing of the available 
consumptive water between water users. Some of the major debates in past water plans have been about how available water is shared between different classes of water rights.

The Guide to the proposed Basin Plan (MDBA 2010:171) indicates that waterresource plan accreditation will include the requirement to specify the consultative arrangements upon which the water-resource plan will be developed. This ought to be expanded to set out requirements to ensure that procedural fairness principles and other means for addressing distributional equity as described in the literature are applied.

\section{Governance at a Regional Level}

\section{Coordination}

As was discussed in the introduction, the Basin Plan will be relying on the collaboration of a number of players to achieve its desired outcomes in each valley. In each basin, State responsibilities for water-allocation planning, management of environmental water, water-entitlement management, operation of water infrastructure, natural-resource investment, and various elements of land and water-quality management are split between multiple State agencies. Additionally, Commonwealth agencies responsible for Commonwealth environmental water holdings and allocation of Commonwealth funds under various relevant programs will be involved. Coordination of these agencies around the achievement of common regional outcomes and targets will be very challenging. Current mechanisms are not sufficient.

\section{Funding}

It is clear that the Commonwealth has invested heavily in the Basin Plan and has committed to continue to do so. This level of investment is not reflected, however, in all current State planning processes.

Lower-cost approaches are appropriate in situations where the risks and competition for water are low. Applying them to high-risk, high-competition cases, where there are real impacts on water users and substantial risks to the environment, is, however, inviting difficulty and putting at risk the achievement of Basin Plan outcomes and the value of returning water to the environment.

Accreditation processes need to include assessment of resourcing to deliver the necessary rigour to planning and management of water at the regional level. 
Agreements about funding commitments and cost sharing between basin States and the Commonwealth are a critical underpinning. In the end, you get what you pay for.

\section{References}

Bates, B., Walker, K., Bears, S. and Page, S. 2010, Incorporating climate change in water allocation planning, Waterlines Report Series No. 28, May 2010, National Water Commission, Canberra.

Folke, C., Carpenter, S., Elmqvist, T., Gunderson, L., Holling, C. S. and Walker, B. 2002, Resilience and Sustainable Development: Building adaptive capacity in a world of transformations, Environment Advisory Council to the Swedish Government, Stockholm.

Hamstead, M. 2008, The national plan for water-opportunities and risks for the irrigation industry, Discussion Paper, April 2008, Prepared for Irrigation Australia Limited, Hornsby, NSW.

Hamstead, M. 2010, Alignment of water planning and catchment planning, Waterlines Occasional Paper, No. 36, Dec 2010, National Water Commission, Canberra.

Hamstead, M., Baldwin, C. and $\mathrm{O}^{\prime}$ Keefe, V. 2008, Water allocation planning in Australia - current practices and lessons learned, Waterlines Occasional Paper No. 6, April 2008, National Water Commission, Canberra.

Ludwig, F., Kabat, P., van Schaik, H. and van der Valk, M. 2009, Climate Change Adaptation in the Water Sector, Earthscan, London.

Murray-Darling Basin Authority (MDBA) 2010, Guide to the proposed Basin Plan. Volume 1: Overview, Murray-Darling Basin Authority, Canberra. 